\title{
PATTERNS OF TEMPORAL DIFFUSION OF CRIME IN MEXICO
}

\author{
D.E. SANTOS-REYES ${ }^{1} \&$ J.R. SANTOS-REYES ${ }^{2}$ \\ ${ }^{1}$ I'CHI Research, Development and Engineering, Oaxaca, México. \\ ${ }^{2}$ Safety, Accident, Risk and Reliability Analysis Research Group, Seccion de Estudios de Postgrado \\ e Investigación, Escuela Superior de Ingeniería Mecánica y Eléctrica (ESIME), Unidad Zacatenco, IPN, \\ México, D.F.
}

\begin{abstract}
Both academia and government institutions have paid significant attention to approach crime, over the last two decades. It seems that these approaches view crime as an isolated event and very little attention has been given to study the dynamic behaviour of crime through time. To understand the dynamics of crime, organisations need to answer a key question: How does crime evolve through time? This research uses a three parameter logistic function and nonlinear regression process to develop an understanding of the dynamics of crime in Mexico. It seems that crime behaviour is an orderly diffusion process. The patterns of temporal diffusion seem to grow slowly at the beginning, followed by an accelerating and then decelerating growth, culminating in saturation or decline. This might help to a better understanding of the rate of crime change so that better approaches can be formulated for preventing and controlling crime.
\end{abstract}

Keywords: Crime, diffusion, S-curve, systems.

\section{INTRODUCTION}

Until very recently, Mexican institutions seem to approach crime by the trial and error method. Methods and tools of science have enhanced this approach. That is, law enforcement and related institutions are working hard to dismantle long-standing barriers that separate them from scientific methods and communities. On the other hand, there has been an underlying opinion within the academic and analysts' community that the nature of crime has changed $[1,2]$. However, very little attention has been given to study the behaviour of crime as the consequence of inter-related parts of situations or systems. Crime prevention and major investment in crime control depend on a correct understanding of the patterns of temporal diffusion of crime. To foster this understanding, this research project addresses the following questions: How does crime change? Does it follow the S-curve? Are crime changes predictable? Is the rate of crime change increasing? In terms of a testable hypothesis regarding shape, path and dynamics, the most precise hypothesis can be formulated as follows: $\mathrm{H}_{1}$ : Crime progress on a primary dimension follows an S-shaped growth curve. The research question is verified through collecting data from prevailing publications. In the remaining sections of the paper, the literature review, method, results and conclusions and further research are presented.

\section{CRIME SCIENCE}

\subsection{Rates of change of crime}

By trying to understand the nature of today's control of crime, it seems that there is something unique and it has to do with the rate of change. Change in technological, social, political, scientific research, etc., is happening all around. Is crime progress predictable? How does crime 
change? In terms of a testable hypothesis regarding shape, path and dynamics of crime change, the research hypothesis can be formulated as follows: $\mathrm{H}_{1}$ : Crime evolve on a primary dimension following an S-shaped growth curve. Science has been used to explain why crime situations have evolved as they have over time. For example, Sirén [3] developed regression models that describe the changes in the assault rate in Finland between 1950 and 2000. Gutauskas et al. [4] discuss the political, socio-economic, organisational and cultural issues that influence the dynamics of change in organised crime in Lithuania from the late 1980s to the early 2000s. It is contended that the interpretation, explanation and forecasting of crime trends are the basic tasks in macro criminology. Lawton et al. [5] use time series models to measure the effectiveness of a programme called 'Safe Streets' during its first 18 weeks of operation in Philadelphia, USA. Seager [6] uses multiple regressions analysis to analyse violent men's impulsivity and self-schemas for a hostile world. On the other hand, Kivivuori [7] studies the rate of murdering in Finland between 1950 and 1999. Similarly, the adolescent female delinquency rate has grown faster in the Netherlands than the corresponding rates among boys [8]. Schehr [9] seeks to assess current trends in the application of risk discourse as a way to facilitate eradication of non-normative deviant behaviour. He argues that conventional risk assessment serves the ideological purpose of marginalising undesirable groups, which leads to the creation and proliferation of technological and behavioural modes of social control. Buffington [10] contends that crime has followed well-defined patterns since the Mexican independence era. It is argued that the Mexican justice system consolidated through time but finally superseded. Piccato [11], on the other hand, analyses the perception of crime during the last century in Mexico City. Several crime issues, such as sources of crime, police and judicial corruption practice, gender violence and juvenile delinquency are addressed. It further discussed the reactions of urban communities and civil organisations against crime. Finally, Skogan and Hartnett [12] discuss the shape of the diffusion curve that describes the pace of adoption of a technology and examine the factors associated with the adoption and the extent to which the innovation was actually used in municipal police departments.

\section{THE CONTEXT OF CRIME IN MEXICO}

\subsection{The situation}

Anyone who has actually observed the Mexican public security management situation will understand that crime, impunity and corruption are all interrelated. New kinds and more organised crime, such as human and weapon smuggling, drug trafficking and mass murdering have emerged over the last few years. Figure 1 exhibits the situation as an overall structure of the situation in recursive levels. It intends to describe the whole system's constituents, how the constituent elements are related to each other and the key characteristics of the components and their relationship.

\subsubsection{The law enforcement system}

The federal, states and district executives are at the top level of the law enforcement system. Their main function is inter alia to execute policies and plans to provide security to the whole country. The next level of the law enforcement system consists primarily of the ministries of public security (SSPs) and the general attorney of the republic (PGR); also, there are attorney's offices at state level (PGJEs) and the Federal District (PGJDF). The SSP essentially consists of the federal police force that has been increasing in size over the last few years (Fig. 2). They 


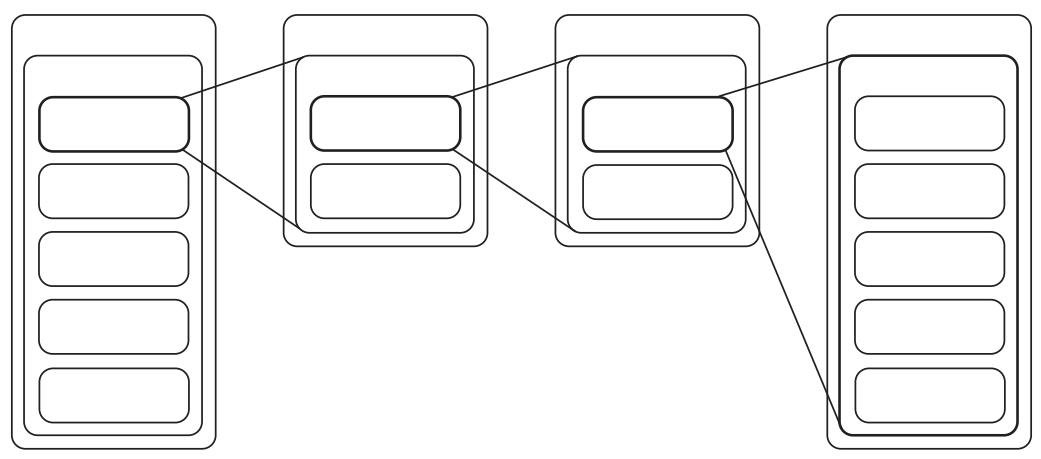

Figure 1: The structure of the control of crime situation in Mexico.

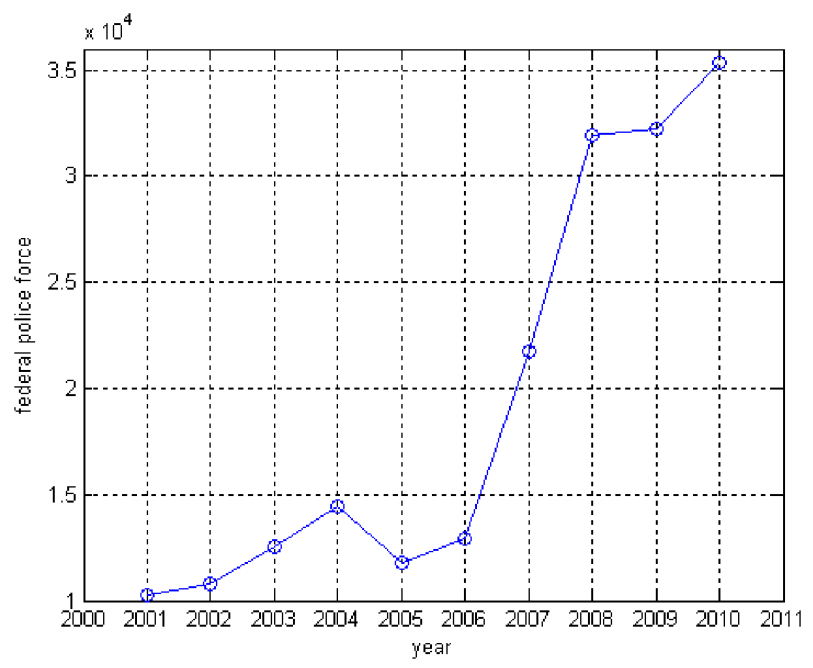

Figure 2: Increasing federal police force.

all are in charge of upholding the rule of law. However, it seems that the preferred approach of the law enforcement system is coersive rather than effective control of crime.

\subsubsection{The judicial system}

The judicial system is intended to ensure the compliance of the Mexican Constitution over the legislations and edicts by the federal executive, including the state executives or the legislative system. In general, the Mexican legal system is built on a civil law framework. This system focuses primarily on the text of actual laws than on prior court decisions. In other words, one studies the law and makes the best argument, given the facts. Because of the endemic practice of corruption, impunity and bribery, very often inappropriate political interferences in the legal system deny Mexicans the right to a fair and impartial justice.

\subsubsection{The legislative system}

This system is in charge of legislating and deliberating new laws, policies, plans and programmes with the aim to provide a better future for the people of the nation. However, 
whenever the members of the legislative system, including members of the executive system and politicians, gather to discuss the existing state of affairs that includes crime, with a view to creating a new vision of the future, they very often begin by acknowledging the accepted categories by which those affairs are discussed and analysed. They all speak of health, education, welfare and security just as if it were not the same person, who is well or ill, educated or uneducated, nurtured or mal-nurtured, cared for or abandoned and victim or offender. In the case of crime, probably it is more important to ask: how shall Mexicans ever conceive a new vision if they are bound by the categorisation that delivered crime problems to them in the first place? Moreover, before deciding whether the whole system is fit for purpose, perhaps it is better to decide what that purpose is. It seems that Mexican law makers and politicians approach crime in a reductionistic manner rather than seeing it as the consequence of systemic interactions between the elements of the whole system.

\subsubsection{The social system}

The last general survey reports that the Mexican population exceeds 100 million inhabitants. Everything is steadily improving in the world of very few inhabitants, while the quality and standard of life of millions are getting steadily worse. In general, Mexicans, in civil associations, or in NGO, have realised demonstrations throughout the country to express their concern about the increasing rate of crime, such as violence against women, kidnappings, murdering, violation of the rights of minority groups, murdering of journalists, disappearances, drug trafficking and associated violence, fraudelent elections and the excessive use of force in the practice of policing. Significant effort has been made to protect Mexicans against corruption, impunity and crime over the last decades. However, it has become apparent that whatever the vast majority of Mexicans do to affect real change, powerful influences have tended to maintain the status quo ante. The whole system needs to innovate.

\subsubsection{The crime system}

It is well documented that there are many criminal organisations, including drug trafficking organisations, smuggling gangs, alien smuggling networks, foreign transnational organisations, such as Russian, Chinese, Japanese, etc., domestic insurgent and terrorist organisations and foreign terrorist organisations, operating in Mexico [13]. They are evolving into more sophisticated modus operandi to survive in a very competitive environment. Also, the more traditional forms of crime, such as robberies/assaults, burglaries, murdering/injuries, rape and sexual violence, child pornography, racism/discrimination, kidnappings and antisocial behaviour are expanding and adapting to the modern forms of the Mexican's life style. Moreover, criminals are evolving into new forms of crime with modern information technology to commit crimes, such as frauds, piracy and different forms of cybercrime and is increasing with time (Fig. 3).

\subsection{The system-in-focus and data gathering}

The system of interest or in focus here is the crime system (Fig. 1). In particular, the system-in-focus is the crime committed at the state jurisdiction level. There has been a significant effort by the researchers and experts in gathering and analysis of crime data, over the last few years. However, a readymade crime database does not exist for the study of crime 


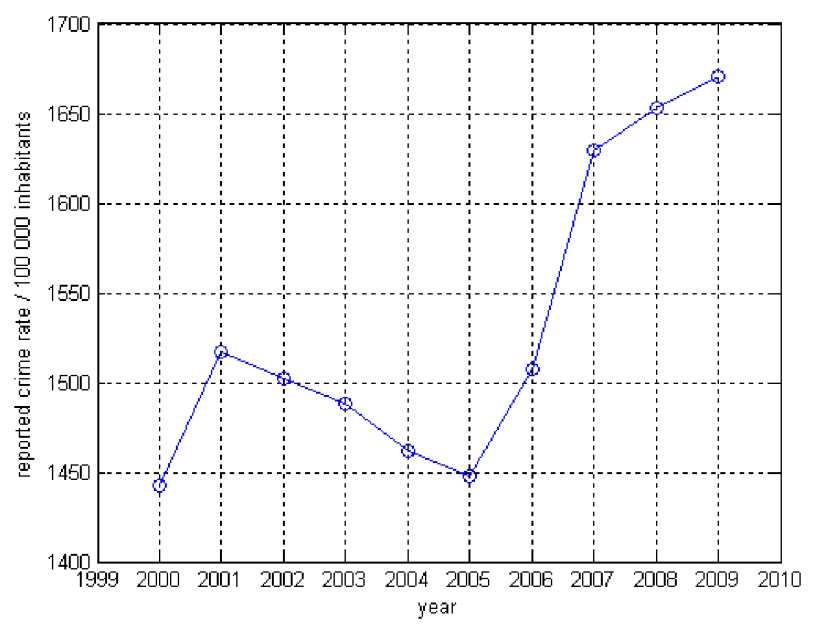

Figure 3: Increase in crime over the last decade.

behaviour and the patterns of temporal and spatial diffusion of criminal systems in Mexico. In this research project, crime data has been gathered, following the historical method proposed by Golder [14]. The possible benefits of using a historical method include lower survival and self-report bias in both upwards and downwards direction. Moreover, one can assess causality through longitudinal analysis and gain new insights from a fresh reading of the Mexican contemporary history. A brief description of the sample selection, sources and procedure for data collection is provided below.

\subsubsection{Sample selection}

Two main criteria have been used to select data categories: (a) data directly related to the performance of criminal systems extracted from prior research and (b) data not directly related to the criminal systems but that reflects the behaviour of crime. That is, categories of crime have been selected such that they include some data that has been investigated in prior research, for example, serious crime under state or federal jurisdiction and others that have not been researched, for example, the growing rate of private security business over the years. This might enable to compare results with prior studies and validate the findings of the present research project. In this research project, published data directly related to the performance of crime has been selected in order to test $\mathrm{H}_{1}$. Based on this criterion, the following crime data categories have been chosen: serious crimes under federal and state jurisdictions have been gathered. The sample crosses a broad spectrum of crime.

\subsubsection{Sources of crime data}

The information required for this study is data on criminal system performance for various types of crime at different epochs of their evolution. The primary sources of the data are reports in technical journals, and publications of the PGR, PGJEs and PGJDF, white papers published by R\&D organisations and universities and annual reports of NGOs. In addition, past and current crime performance has been recorded from the mass media and press releases. 


\subsubsection{Procedure of data gathering}

In general, the phases for data collection of the historical method as proposed by Golder [14] have been followed throughout the data gathering process. A specific research question is addressed: How do crime temporal patterns of diffusion evolve? As discussed above, the first step of the data collection process is to access and gather available crime data from different sources, such as the crime data reported by Piccato [15], crime data reported by Arango and Medina [16], crime data compiled by the PGR and crime data reported by PJGDF and from other sources. The resulting data set includes information on a wide range of crimes. It has been straightforward to establish authorship, date of publication and verification of that data has been the result of scientific inquiry. Moreover, Piccato, Arango and Medina are widely recognised experts on Mexican crime issues.

\section{PATTERNS OF TEMPORAL DIFFUSION OF CRIME}

First, the identification of different categories of crime and the performance attributes in each category is presented. Second, the findings on the research question regarding the shape, path and dynamics of the crimes in Mexico are discussed.

\subsection{Crime categories and performance attributes}

Broadly speaking, crime data categories have been classified as latent and patent crime data. In turn, these categories have been further broken down into serious crimes under states jurisdiction or misdemeanour and serious crimes under federal jurisdiction. Latent data refers to the data that is not directly related to crime but reflects the behaviour of the crime, for example, the growth rate of insurances against crime, while the patent crime data directly relate to the performance of criminal systems, for example, murdering rates. The later category has been addressed by various researchers, such as those mentioned in the previous section. For the purpose of this paper, the patent crime data gathered and analysed by Piccato [15], Arango and Medina [16] are used to study the temporal diffusion of crime in Mexico.

Many crime issues, such as cybercrime, copy right or piracy, bullying, racial discrimination, disappearances, violation of rights of indigenous people, etc., may not be readily distinguishable to the researchers for many reasons. For example, very often, crime control institutions tend to manipulate the facts about crime committed by the law enforcement institutions. It is very well recognised that a major reason for the inefficient crime control is the lack of an effective crime data collection and analysis system, at both state and national level.

When testing the S-shaped curves, it is recommended by Foster [17] and Altshuller [18] to use performance of the system as the key independent variable. In each category, at a particular phase of crime evolution, certain dimensions of performance assume primacy. Based on the historical description of crime, it is fairly easy to identify these dimensions. In choosing metrics of performance, output per unit of input was taken into consideration carefully.

\subsection{Shape, path and dynamics of crime}

In $\mathrm{H}_{1}$, it is contended by the authors that crime evolves through $\mathrm{S}$-curves. Crime performance was plotted on the $y$-axis against time on the $x$-axis (Figs. 4-6). These plots suggest that crime has a slow start and a sudden fast growth. As can be seen in these figures, it is found that a single S-shaped path with a single inflection point is followed by plateau or maturity in all categories of data. 


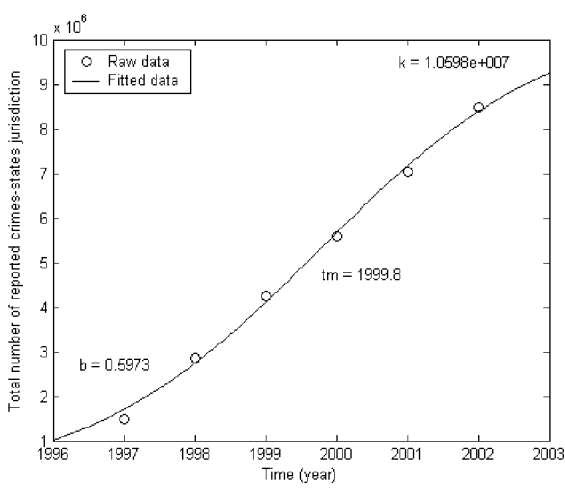

(a)

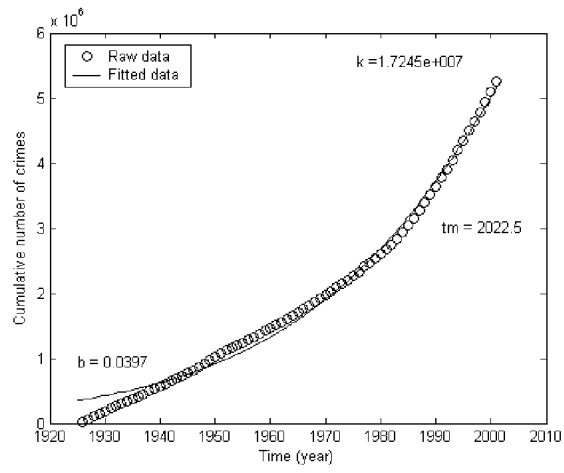

(c)

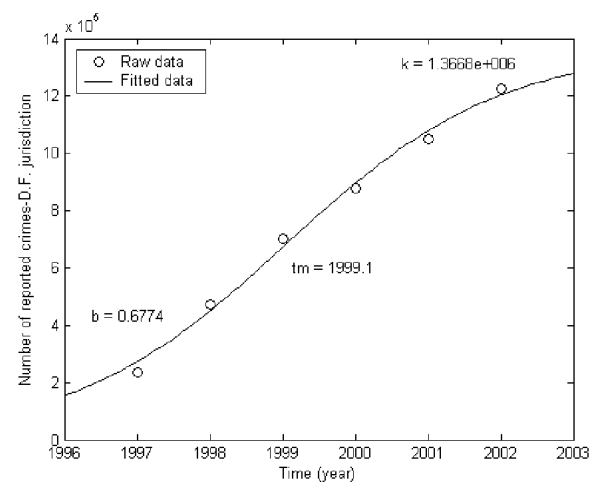

(b)

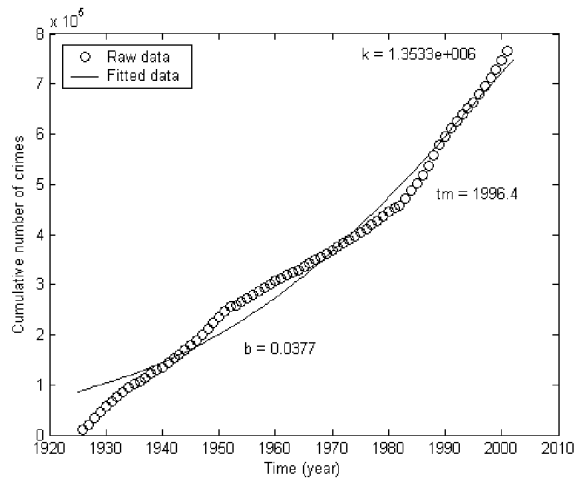

(d)

Figure 4: The diffusion of crime under state jurisdiction or misdemeanour in Mexico and Mexico D.F.

To verify that crime evolution follows the logistic function $\left(\mathrm{H}_{1}\right)$, the following tests were realised. First, a three parameter logistic function was fit to the crime data, as reported by Arango and Medina [16] and Piccato [15] (Fig. 4). As hypothesised, these curves reveal a single S-shaped curve:

$$
Y(t)=\frac{k}{1+e^{-b\left(t-t_{m}\right)}}
$$

where $Y(t)$ represents the S-curve growth through time of a population or process, $Y$. This is often called as the logistic model. Three parameters control the shape of the sigmoid growth trajectory: $b$ controls the steepness (diffusion or growth rate) of the model; $k$ denotes the asymptotic limit (or saturation level) and $t_{m}$ denotes the middle or inflection point. It should be noted that the inflection point occurs at $k / 2$, where the growth rate $(d Y / d t)$ is at a maximum. Also note that $k$ is sometimes referred to as the 'carrying capacity'. A convenient notation for the diffusion rate, $b$, is $\Delta t$, where $\Delta t$ is the time the process takes to grow from $10 \%$ to $90 \%$ of the saturation level, $k$. Approximately the same length of time is required for the process to grow from $1 \%$ to $50 \%$. The nonlinear regression process, as described by [19], and Matlab programming language were used to estimate the parameters of the model over the entire data sample. Second, 


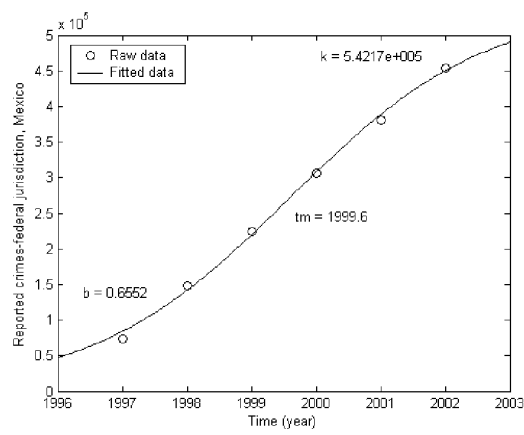

(a)

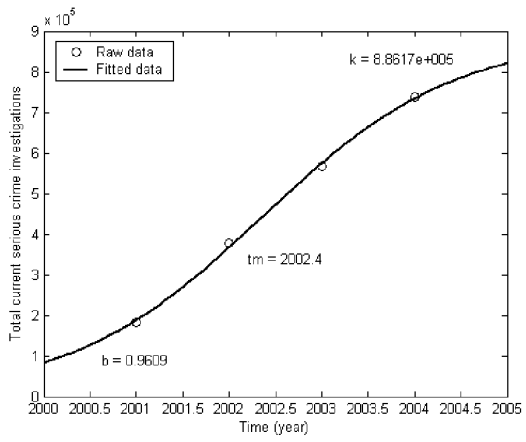

(c)

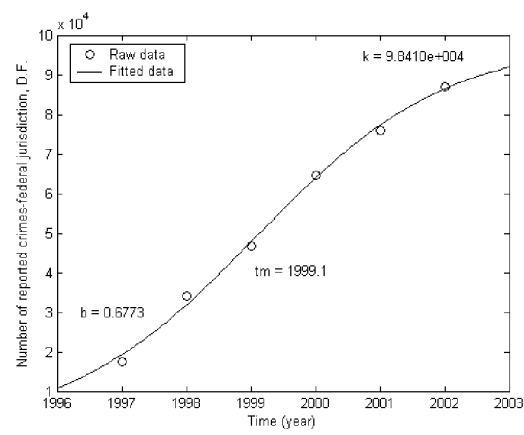

(b)

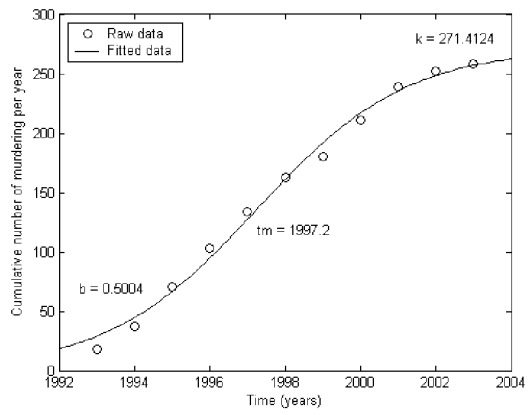

(d)

Figure 5: The diffusion of crime under federal jurisdiction in Mexico and Mexico D.F.

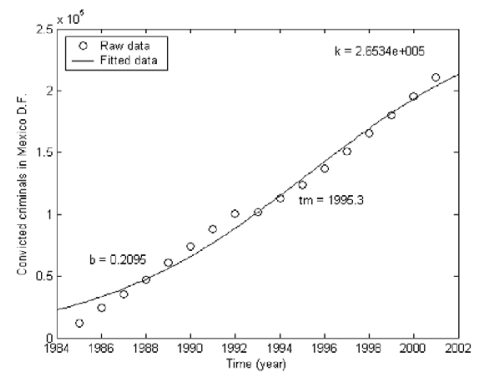

(a)

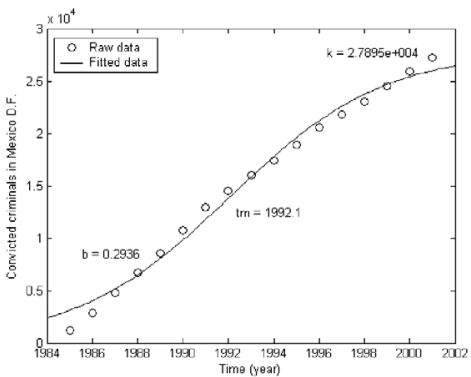

(c)

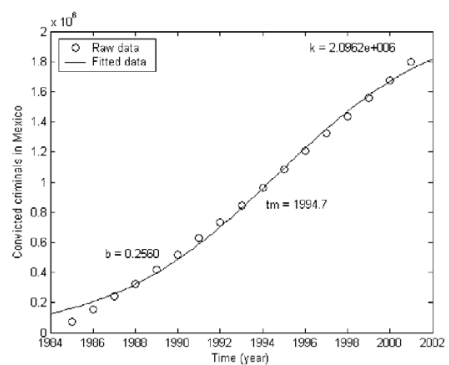

(b)

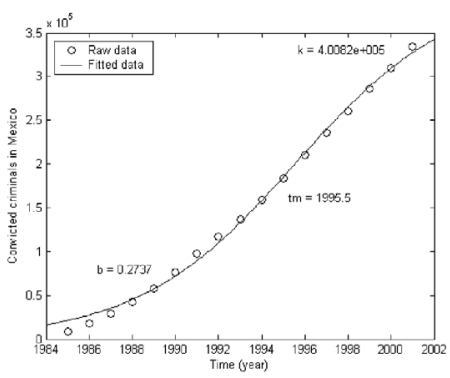

(d)

Figure 6: Convicted criminals a diffusion process in Mexico and Mexico D.F. 
crime data, as published by Arango and Medina [16], PGR [20], and Jornada [21], also seem to exhibit S-curves (Fig. 5). Again, the three parameter logistic function was used to fit the entire series of data. In general, the goal is to test how well an S-curve fits on the whole sample for a longer period of time and for the entire country, and whether it fits better on a sub-sample, i.e., for a particular state, such as Mexico D.F. Finally, crime data, as published by Arango and Medina [16], also exhibit the S-shaped path. Once again, the logistic function was used to fit the crime data to the S-curve pattern. Figure 6 shows the resulted curves.

It was found that for the crime categories with an apparent single S-shaped curve, the three parameter logistic function provides a good fit with the data, as reported by Arango and Medina [16], and Piccato [15] (Fig. 4 and Tables 1-4). For the remaining data, as published by Arango and Medina [16], PGR [20] and Jornada [21], S-shaped curves fit well over the sub-samples. For both data sets for the entire country and for Mexico D.F. with an apparent

Table 1: Analysis of variance of reported misdemeanour crime in Mexico (Fig. 4a).

\begin{tabular}{lccc}
\hline Source & d.f. & SS & MS \\
\hline Total & 6 & $3.4661 \mathrm{e}+009$ & \\
$\quad$ Due to regression & 2 & $3.3874 \mathrm{e}+009$ & $1.6937 \mathrm{e}+009$ \\
$\quad$ Residuals & 3 & 801016 & $2.6701 \mathrm{e}+005$ \\
\hline
\end{tabular}

Table 2: Analysis of variance of reported misdemeanour crime in Mexico D.F. (Fig. 4b).

\begin{tabular}{lccc}
\hline Source & d.f. & SS & MS \\
\hline Total & 6 & $6.7587 \mathrm{e}+011$ & \\
$\quad$ Due to regression & 2 & $6.6669 \mathrm{e}+011$ & $3.3335 \mathrm{e}+011$ \\
$\quad$ Residuals & 3 & 65308654 & $2.1770 \mathrm{e}+007$ \\
\hline
\end{tabular}

Table 3: Analysis of variance of reported misdemeanour crime in Mexico (Fig. 4c).

\begin{tabular}{lccc}
\hline Source & d.f. & SS & MS \\
\hline Total & 76 & $1.5015 \mathrm{e}+014$ & \\
$\quad$ Due to regression & 2 & $1.5378 \mathrm{e}+014$ & $7.6888 \mathrm{e}+013$ \\
$\quad$ Residuals & 73 & $4.8316 \mathrm{e}+011$ & $6.6187 \mathrm{e}+009$ \\
\hline
\end{tabular}

Table 4: Analysis of variance of reported misdemeanour crime in Mexico D.F. (Fig. 4d).

\begin{tabular}{lccc}
\hline Source & d.f. & SS & MS \\
\hline Total & 76 & $3.0334 \mathrm{e}+012$ & \\
$\quad$ Due to regression & 2 & $3.1554 \mathrm{e}+012$ & $1.5777 \mathrm{e}+012$ \\
$\quad$ Residuals & 73 & $2.5586 \mathrm{e}+010$ & $3.5049 \mathrm{e}+008$ \\
\hline
\end{tabular}


Table 5: Analysis of variance of reported crime under federal jurisdiction in Mexico (Fig. 5a).

\begin{tabular}{lccc}
\hline Source & d.f. & SS & MS \\
\hline Total & 6 & $1.0275 \mathrm{e}+011$ & \\
$\quad$ Due to regression & 2 & $9.9543 \mathrm{e}+010$ & $4.9772 \mathrm{e}+010$ \\
$\quad$ Residuals & 3 & 12770544 & 4256848 \\
\hline
\end{tabular}

Table 6: Analysis of variance of reported crime under federal jurisdiction in Mexico D.F. (Fig. 5b).

\begin{tabular}{lccc}
\hline Source & d.f. & SS & MS \\
\hline Total & 6 & $3.4661 \mathrm{e}+009$ & \\
$\quad$ Due to regression & 2 & $3.3874 \mathrm{e}+009$ & $1.6937 \mathrm{e}+009$ \\
$\quad$ Residuals & 3 & 801016 & $2.6701 \mathrm{e}+005$ \\
\hline
\end{tabular}

Table 7: Analysis of variance of federal crime initial investigations (Fig. 5c).

\begin{tabular}{lccc}
\hline Source & d.f. & SS & MS \\
\hline Total & 4 & $1.7196 \mathrm{e}+011$ & \\
$\quad$ Due to regression & 2 & $1.8322 \mathrm{e}+011$ & $9.1609 \mathrm{e}+010$ \\
$\quad$ Residuals & 1 & 40723405 & 40723405 \\
\hline
\end{tabular}

Table 8: Analysis of variance of women murdering in CD Juarez (Fig. 5d).

\begin{tabular}{lccc}
\hline Source & d.f. & SS & MS \\
\hline Total & 11 & $7.3655 \mathrm{e}+004$ & \\
$\quad$ Due to regression & 2 & $7.3371 \mathrm{e}+004$ & $3.6686 \mathrm{e}+004$ \\
$\quad$ Residuals & 8 & 4.2549 & 0.5319 \\
\hline
\end{tabular}

single S-shaped curve, the three parameter logistic function was used to fit (Figs 5 and 6, and Tables 5-12).

In summary, the hypothesis of a single S-shaped growth in crime performance is supported for all data categories. The importance of this finding is that a crime policy-maker expecting that crime rate is lowering may emphasise on current practice. That is, crime usually is considered as a static phenomenon; however, as exhibited in Figs. 4-6, crime is a evolving phenomenon. This may require creative thinking to address crime effectively.

\subsection{Discussion}

Figure 4 exhibits both the raw and the fitted data on crime under state jurisdiction or misdemeanour in Mexico and Mexico D.F. as diffusion processes. Figure $4 \mathrm{a}$ and $\mathrm{b}$ show the 
behaviour of crime under state jurisdiction in Mexico as a whole, and in Mexico D.F. respectively. As can be seen in these curves, the crime data set, as reported by Arango and Medina (2006), with apparent sigmoid-shaped, the three parameter logistic function provides a good fit with the data set. The three parameters that control the shape of the growth path of crime shown in Fig. 4a are the diffusion rate, $b=0.5973$, the inflection point, $t m=1999.8$ and saturation level, $\mathrm{k}=1.0598 \mathrm{e}+007$, while the diffusion rate, $\mathrm{b}=0.6774$, the inflection point, $\mathrm{tm}=$ 1999.1 and the saturation level, $\mathrm{k}=1.3668 \mathrm{e}+006$ correspond to the $\mathrm{S}$-shaped curve shown in Fig. 4b. Tables 1 and 2 show the analysis of variance of both crime data sets. The growth rate of crime in Mexico D.F. is slightly higher than for the entire country $(0.6774>0.5973)$. It seems, in both cases, that growth of crime has started to decline as evidenced by the inflection points 1998.8 and 1999.1, respectively. However, this is not totally true, when a longer period of time is considered, as shown in Fig. $4 \mathrm{c}$ and d. As depicted in these curves, for the crime data set for a longer period of time, as reported by Piccato (2006), with apparent $\mathrm{S}$-shaped path, the three parameter logistic function provides good fit. The corresponding parameters for the S-shaped curve of the misdemeanour crime in Mexico as a whole are the diffusion rate, $\mathrm{b}=0.0397$, the inflection point, $\mathrm{tm}=2022.5$ and the saturation level, $\mathrm{k}=$ $1.7245 \mathrm{e}+007$. The diffusion rate, $\mathrm{b}=0.0377$, the inflection point, $\mathrm{tm}=1996.4$ and the saturation level, $\mathrm{k}=1.3533 \mathrm{e}+006$ correspond to the misdemeanour crime rate in Mexico D.F. In this case, crime growth rate in Mexico D.F. is slightly lower than in the entire country $(0.0377<0.0397)$. The inflection point for the crime growth in Mexico D.F. is very similar to the inflection point of the curve shown in Fig. 4b, that is, $\mathrm{tm}=1999.1$ and $\mathrm{tm}=1996.4$, respectively. In contrast, the growth rate, as shown in Fig. 4c, is much lower than the crime growth rate shown in Fig. 4a, that is, $0.0397<0.5973$. In other words, the growth of misdemeanour crime for a longer period of time, as shown in Fig. $4 \mathrm{c}$, has not reached the inflection point, which is $\mathrm{tm}=2022.5$. The growth of misdemeanour crime in Mexico D.F., on the other hand, has already passed the middle point $(\mathrm{tm}=1999.8)$. Tables 3 and 4 report the analysis of variance of misdemeanour crime in Mexico as a whole and in Mexico D.F., in particular, respectively.

Similarly, Fig. 5 exhibits curves as diffusion process, that is, serious crimes under federal jurisdiction through the years. It should be noted that crime performance shown in Fig. $5 \mathrm{~d}$ is not strictly categorised as federal, but it has attracted federal attention over the last few years. As shown in Fig. 5a, for the crime data set, as reported by Arango and Medina (2006), with $\mathrm{S}$-shaped curve, the three parameter logistic function provides good fit. The parameters that describe the dynamics of the crime growth path are the following: the diffusion rate, $\mathrm{b}=0.6552$, the inflection point, $\mathrm{tm}=1999.6$ and the saturation level, $\mathrm{k}=5.4217 \mathrm{e}+005$. Equation (1) provides good fit with the data set, as reported by Arango and Medina (2006), regarding the federal crime in Mexico D.F. As shown in Fig. 5b, the parameters that define the growth curve are the diffusion rate, $b=0.6773$, the inflection point, $t \mathrm{~m}=1999.1$ and the saturation level, $k=9.8410 \mathrm{e}+004$. From these two S-shaped curves, it can be said that the federal crime growth rate and the middle point of the crime growth, in both (a) and (b), are very similar in both curves, that is, $0.6552 \cong 0.6773$ and $1999.6 \cong 1999.1$, respectively. Tables 5 and 6 report the analyses of variance that support the good correlation of the raw and fitted data, respectively. On the other hand, for the data set, as reported by the PGR (2006), with an S-shaped path, the logistic function provides good fit (Fig. 5c). Like in the previous cases, the parameters that describe this $S$-curve are the diffusion rate, $b=0.9609$, the inflection point, $\mathrm{tm}=2002.4$ and the saturation level, $\mathrm{k}=8.8617 \mathrm{e}+005$. It should be emphasised that this curve does not relate directly to criminal system performance, but it 
reflects indirectly to the dynamics of criminal systems. For registered murdering of women in CD Juarez data set (Jornada 2006), with S-shaped path, the logistic function fits very well (Fig. 5d). The corresponding parameters that define this curve are the diffusion rate, $\mathrm{b}=0.5004$, the inflection point, $\mathrm{tm}=1997.2$ and the saturation level, $\mathrm{k}=271.4124$. Tables 7 and 8 summarise the analysis of variance that support the claim that the logistic function fits very well with crime raw data sets. As noted above, the murdering of women in CD Juarez in the northern state of Chihuahua is not strictly categorised as federal crime, but due to pressures from different organisations, it attracted the federal government's attention.

Finally, Fig. 6 shows curves as the cumulative number of convicted criminals under federal and state jurisdiction in Mexico and Mexico D.F. through time. The diffusion processes as depicted by the $\mathrm{S}$-shaped curves were fitted to the data reported by Arango and Medina (2006), by using eqn (1). Figure $6 \mathrm{a}$ and $\mathrm{b}$ shows the dynamics of convicted criminals under state jurisdiction for Mexico D.F. and Mexico, respectively. The three parameters that control the shape of the growth path shown in Fig. 6a are the following: the diffusion rate, $b=0.2095$, the inflection point, $\mathrm{tm}=1995.3$ and the saturation level, $\mathrm{k}=2.6534 \mathrm{e}+005$. And the parameters that shape the S-curve of the convicted criminals under federal jurisdiction in Mexico D.F. (Fig. 6c) are the diffusion rate, $b=0.2936$, the inflection point, $t m=1992.1$ and the saturation level, $\mathrm{k}=2.7895 \mathrm{e}+004$. Tables $9-12$ provide the analysis of variance that shows

Table 9: Analysis of variance of convicted criminals under state jurisdiction in Mexico D.F. (Fig. 6a).

\begin{tabular}{lccc}
\hline Source & d.f. & SS & MS \\
\hline Total & 17 & $5.8653 \mathrm{e}+010$ & \\
$\quad$ Due to regression & 2 & $5.9241 \mathrm{e}+010$ & $2.9620 \mathrm{e}+010$ \\
$\quad$ Residuals & 14 & 126096001 & $9.0069 \mathrm{e}+006$ \\
\hline
\end{tabular}

Table 10. Analysis of variance of convicted criminals under state jurisdiction in Mexico (Fig. 6b).

\begin{tabular}{lccc}
\hline Source & d.f. & SS & MS \\
\hline Total & 17 & $4.9145 \mathrm{e}+012$ & \\
$\quad$ Due to regression & 2 & $4.6043 \mathrm{e}+012$ & $2.3022 \mathrm{e}+012$ \\
Residuals & 14 & $1.3681 \mathrm{e}+010$ & $9.7722 \mathrm{e}+008$ \\
\hline
\end{tabular}

Table 11. Analysis of variance of convicted criminals under federal jurisdiction in Mexico D.F. (Fig. 6c).

\begin{tabular}{lccc}
\hline Source & d.f. & SS & MS \\
\hline Total & 17 & $1.0993 \mathrm{e}+009$ & \\
$\quad$ Due to regression & 2 & $1.0608 \mathrm{e}+009$ & $5.3039 \mathrm{e}+008$ \\
$\quad$ Residuals & 14 & 2237512 & $1.5982 \mathrm{e}+005$ \\
\hline
\end{tabular}


Table 12. Analysis of variance of convicted criminals under federal jurisdiction in Mexico (Fig. 6d).

\begin{tabular}{lccc}
\hline Source & d.f. & SS & MS \\
\hline Total & 17 & $1.8371 \mathrm{e}+011$ & \\
$\quad$ Due to regression & 2 & $1.8629 \mathrm{e}+011$ & $9.3147 \mathrm{e}+010$ \\
$\quad$ Residuals & 14 & 78189270 & $5.5849 \mathrm{e}+006$ \\
\hline
\end{tabular}

the robustness of these results. As can be seen in these curves, the growth rate of convicted criminals under federal jurisdiction is higher than the growth rate of convicted criminals under state jurisdiction $(0.2936>0.2095)$. Thus, the fast increase the number of convicted criminals under federal jurisdiction $(\mathrm{tm}=1992.1)$ might reflect an improvement of the efficacy of the crime control system. However, it also means that serious crimes under federal jurisdiction are increasing rapidly over the last few years. In contrast, the low growth rate of convicted criminals under state jurisdiction might reflect that crime, in general, is decreasing in Mexico D.F. This evidence is also shown in Fig. $4 \mathrm{~b}$ and d. On the other hand, Fig. $6 \mathrm{~b}$ and $\mathrm{d}$ show curves that describe the dynamics of convicted criminals under state and federal jurisdiction in Mexico as a whole. The parameters that describe the patterns of convicted criminals under state jurisdiction for the entire country (Fig. 6b) are the following: the diffusion rate, $\mathrm{b}=0.2560$, the inflection point, $\mathrm{tm}=1994.7$ and the saturation level, $\mathrm{k}=2.0962 \mathrm{e}$ +006 . The diffusion rate, $\mathrm{b}=0.2737$, the inflection point, $\mathrm{tm}=1995.5$ and the saturation level, $\mathrm{k}=4.0082 \mathrm{e}+005$ correspond to the $\mathrm{S}$-curve (Fig. $6(\mathrm{~d})$ ) for the convicted criminals under federal jurisdiction. It can be seen that the growth rate of convicted criminals $(0.2737)$ is lower than the growth rate of reported criminals (0.6552) as shown in Fig. 5a. This might either show the inefficacy of the judiciary and crime control systems to approach crime, which leave many criminals free on the Mexican streets or shows the crime reporting systems as ineffective. Similar conclusions can be drawn from the fact that the growth rate of convicted criminals (0.2560), as shown in Fig. 6b, is much lower than the growth rate (0.6774), as shown in Fig. 4b, of reported criminals in Mexico D.F. This might be an indication of the high level of impunity and corruption that are believed to be endemic in the country.

To summarise, the hypothesis of an S-shaped growth curve in crime performance is accepted as supported by both the crime data sets of Mexico as a whole and for the samples of crime data for Mexico D.F. The importance of these findings is that an analyst may use the logistic function to study the dynamics of crime so that better plans for reducing and preventing crime can be formulated. From these results, it can be said that crime performance evolves through S-shaped curves. The path of crime evolution seems to be predictable, and the rate of crime change or growth increases over time. However, it should be emphasised that the study described here has several limitations. First, there was a need to limit the analysis to only those published categories of crime data because of the time-consuming nature and difficulty of data gathering and analysis. Second, the analysis of performance did not include the performance of the law enforcement system. Third, people or social systems performance based on their behaviour with respect to crime was not incorporated in the analysis either. Finally, despite the efforts spent in the process of data collection by different organizations and researchers, the existing crime data sets are incomplete. 


\section{CONCLUSIONS AND FURTHER RESEARCH}

This paper presented the results regarding the patterns of temporal diffusion of crime, considering the cases of crime in Mexico through the use of a three logistic function model and the nonlinear regression process to fit the model to all the crime data sets. Although the results of this study are not strictly conclusive, it has several implications for policy-makers and decision-makers. First, using the S-curve to predict the performance of criminal systems may help to better visualise the measures for reducing and preventing future crime acts. Second, the continuous emergence of new forms of crime and the steady growth of crime performance suggest that relying on the status quo is not the best approach to crime prevention and reduction. Moreover, the S-shaped patterns of temporal diffusion have a slow growth at the beginning, followed by accelerating and then decelerating growth, culminating in saturation. This means that criminal systems adapt through time. Future research includes addressing some of the limitations listed above, and performing several analysis that cover not only patterns of temporal diffusion of other systems, such as judicial, legislative, law enforcement and social systems but also spatial diffusion processes and and how creative design can contribute to prevent the evolution and growth of crime.

\section{REFERENCES}

[1] Griffiths, H. Smoking guns: european cigarette smuggling in the 1990's. Global Crime, 6(2), pp. 185-200, 2004. doi: http://dx.doi.org/10.1080/17440570500096759

[2] Santos-Reyes, D. \& Santos-Reyes, J., Patterns and rates of crime evolution in Mexico, WIT Transactions on the Built Environment, pp. 119-127, 2007.

[3] Siren, R. Trend in Assault: on the relationship between the assault rate and selected social indicators in post-war finland. Journal of Scandinavian Studies in Criminology and Crime Prevention, 3, pp. 22-49, 2002. doi: http://dx.doi.org/10.1080/140438502762467191

[4] Gutauskas, A., Juska, A., Johnstone, P. \& Pozzuto, R., Changing typology of organised crime in a post-socialist lithuania (the late 1980s-Early 2000s), Global Crime, 6(2), pp. 201-221, 2004. doi: http://dx.doi.org/10.1080/17440570500096775

[5] Lawton, B.A., Taylor, R.B. \& Luongo, A.J. Police Officers on drug corners in philadelphia, drug crime, and violent crime: intended, diffusion, and displacement impacts, Justice Quarterly, 22(4), pp. 427-451, 2005. doi: http://dx.doi.org/10.1080/ $\underline{07418820500364619}$

[6] Seager, J.A. Violent Men: the Importance of Impulsivity and Cognitive Schema. Criminal Justice and Behavior, 32(1), pp. 26-49, 2005. doi: http://dx.doi.org/10.1177/ $\underline{0093854804270625}$

[7] Kivivuori, J. Sudden increase of homicide in early 1970s finland. Journal of Scandinavian Studies in Criminology and Crime Prevention, 3, pp. 6-21, 2002. doi: http://dx.doi. org/10.1080/140438502762467182

[8] Gundersen, K. \& Svartdal, F., Evaluation of a norwegian postgraduate training programme for the implementation of aggression replacement training. Psychology, Crime and Law, 11(4), pp. 435-444, 2005. doi: http://dx.doi.org/10.1080/10683160500256610

[9] Schehr, R.C., Conventional Risk Discourse and the Proliferation of Fear, Criminal Justice PolicyReview, 16(1),pp.38-58,2005.doi:http://dx.doi.org/10.1177/0887403404266461

[10] Buffington, R., Periodisation and its discontents: the social construction of crime and criminality in modern Mexico. In Center for U.S.-Mexican Studies. Project on Reforming the Administration of Justice on Mexico. http://repositories.cdlib.org/usmex/prajm/ buffington, 2003. 
[11] Piccato, P., A historical perspective on crime in twentieth-century Mexico City. In Center for U.S.-Mexican Studies. Project on Reforming the Administration of Justice in Mexico, 2003.

[12] Skogan, W.G., \& Hartnett, S.M., The Diffusion of Information Technology in Policing. Police Practice and Research, 6(5), pp. 401-417, 2005. doi: http://dx.doi.org/10.1080/ 15614260500432949

[13] Miro, R.J. \& Curtis, G.E., Organised crime and terrorist activity in Mexico, 1999-2002, The Library of Congress. http://www.loc.gov/rr/frd/terrorism.html, 2003.

[14] Golder, P.N., Historical method in marketing research with new evidence on long-term market share stability. Journal of Marketing Research, 37, pp. 156-172, 2000. doi: http:// dx.doi.org/10.1509/jmkr.37.2.156.18732

[15] Piccato, P., Estadisticas del crimen en Mexico: Series históricas, 1901-2001. In Columbia University. http://www.columbia.edu/ pp143/estadisticascrimen/EstadisticasSigloXX, 2006.

[16] Arango, D. \& Medina, L., Análisis y tendencia del delito en México (1997-2002). In Seguridad Pública en México. http://www.seguridadpublicaenmexico.org.mx/estudios\%20sobre\%20mexico/menu_2, 2006.

[17] Foster, R., Innovation: The Attacker's Advantage. New York: Summit books, 1986.

[18] Altshuller, G., Creativity as an Exact Science. Gordon and Breach, Science Publishers, 1984.

[19] Rawlings, J.O, Pantula, S.G. \& Dickey, D.A., Applied Regression Analysis: A Research Tool. Springer, 1998. doi: http://dx.doi.org/10.1007/b98890

[20] PGR (Procuraduria General de la Republica), Averiguaciones previas activas. In: http:// www.pgr.gob.mx/estadistica/2004_II.1_AP_Activas_Total.pdf, 2006.

[21] Jornada, Numeros de verguenza. In:http://www.jornada.unam.mx/2005/06/06/esp_ juarez/indice_juarez.htm, 2006. 